\title{
Spinal navigation applied to the anterior approach for the resection of thoracic disc herniation: patient series
}

\author{
Angelo Rusconi, MD, Paolo Roccucci, MD, Stefano Peron, MD, PhD, and Roberto Stefini, MD \\ Department of Neurosurgery, Azienda Socio-Sanitaria Territoriale Ovest Milanese, Legnano Civil Hospital, Milan, Italy
}

BACKGROUND Thoracic disc herniation (TDH) represents a challenge for spine surgeons. The goal of this study is to report the surgical technique and clinical results concerning the application of navigation to anterior transthoracic approaches.

OBSERVATIONS Between 2017 and 2019, 8 patients with TDH were operated in the lateral decubitus by means of mini-open thoracotomy. An adapted patient referent frame was secured to the iliac wing. The high-speed drill was also navigated. Intraoperative three-dimensional scans were used for level identification, optimized drilling trajectory, and assessment of complete resection. At 12 months follow up, all patients were ambulatory. Seven out of 8 patients (87\%) experienced a postoperative neurological improvement. We observed 2 postoperative complications: 1 case of pleural effusion and 1 case of abdominal wall weakness.

LESSONS In order to increase the safety of anterior transthoracic discectomy, the authors applied the concepts of spinal navigation to the thoracotomy setting. The advantages of this technique include decrease in wrong-level procedure, continuous matching of intraoperative and navigation anatomical findings, better exposure of the TDH, optimized vertebral body drilling, and minimized risk of neurological damage. In conclusion, the authors consider spinal navigation as an important resource for the surgical treatment of patients with TDH.

https://thejns.org/doi/abs/10.3171/CASE21262

KEYWORDS spine surgery; spinal navigation; image-guided surgery; thoracic disc herniation; thoracotomy; wrong level surgery

The surgical treatment of thoracic disc herniation (TDH) represents a challenge for the spinal surgeon. This is mainly due to the rarity of the condition, the vulnerability of the thoracic spinal cord, and the consequent high risk of neurological deterioration. ${ }^{1-5}$ Several surgical approaches have been developed, in order to achieve proper TDH exposure and cord decompression, increase the safety of the procedure, and ameliorate postoperative outcomes. ${ }^{6-9}$ In addition, intraoperative neuromonitoring techniques have been integrated into the surgical management of patients with $\mathrm{TDH}^{2,9}$ Another important tool in current spinal surgery practice is intraoperative navigation. Although routinely used in posterior approaches for traumatic, degenerative and neoplastic spinal lesions, ${ }^{10}$ image guidance is less commonly incorporated into anterior approaches for TDH surgery. In this study, we describe the use of intraoperative spinal navigation with particular adaptations for transthoracic TDH surgery, and report the data regarding our clinical experience in 8 cases.

\section{Study Description}

Between January 2017 and December 2019, a total number of 8 patients with cord compression due to TDH were consecutively treated with transthoracic approach in our institution. Frankel grade was used to determine the preoperative and postoperative neurological function. Radiological findings concerning the involved level, consistency of TDH, and side of compression were reported (Fig. 1). Postoperative computed tomography or magnetic resonance imaging scans of the thoracic spine were obtained to verify the completeness of TDH removal and spinal canal decompression. Postoperative complications were reviewed and detailed. Patients were all clinically evaluated at discharge from the hospital and at 3,6, and 12 months postoperatively. Minimum follow up was 12 months, and ambulatory status was evaluated at final assessment.

ABBREVIATIONS 3D = three-dimensional; IRF = instrument reference frame; PRF = patient reference frame; TDH = thoracic disc herniation; WLS = wrong-level surgery.

INCLUDE WHEN CITING Published June 28, 2021; DOI: 10.3171/CASE21262.

SUBMITTED April 27, 2021. ACCEPTED May 18, 2021.

(C) 2021 The authors, CC BY-NC-ND 4.0 (http://creativecommons.org/licenses/by-nc-nd/4.0/). 




FIG. 1. Radiological findings in patients with TDH. Sagittal (A) and axial (B) computed tomography reconstructions of a giant, partially calcified T8-9 herniated disc. Sagittal (C) and axial (D) magnetic resonance imaging views of another T8-9 calcified TDH case. In our series, 2 out of 8 patients (25\%) harbored a soft TDH, as shown in this $\mathrm{T} 12-\mathrm{L} 1$ case $(\mathrm{E}$ and $\mathrm{F})$. Note the severe canal stenosis with cord compression in all patients.

\section{Surgical Technique for Image-Guided Transthoracic Discectomy}

Surgeries for all patients were performed under general anesthesia, with selective intubation for lung deflation, and patients were positioned in the lateral decubitus with the operative side up (Fig. 2). The side of the approach was determined according to the affected level, pattern of cord compression, and the relationship with adjacent thoracic and mediastinal structures (diaphragm, lung, heart, esophagus, aorta, and great veins). The patient was secured on a radiolucent operative table, with the spinal column close to the edge of the table. Pressure points were padded, and the upper limbs were positioned in order to allow the table to slide without hindrance. In all cases, patients received intraoperative neuromonitoring (somatosensory and motor evoked potentials). Before the


FIG. 2. A: Patient positioning for a left-sided transthoracic approach. Note the position of the upper limbs and the slight breaking of the table in order to facilitate exposure. The red dot indicates the site of PRF placement. B: Operative room setup. Note the position of the O-Arm, infrared camera, and neuromonitoring device. Operative room personnel: surgeon (green dot), assistant (light green), anesthesiologist (yellow), scrub nurse (light blue), and neurophysiologist (orange). $\mathrm{M}=$ microscope.

exposure of the spine, a three-dimensional (3D) scan imaging was obtained and transferred for navigation (O-Arm, Stealth Station, Medtronic Inc.). We used a particular patient reference frame (PRF), designed for anterior and lateral approaches, which was secured to the iliac wing (Fig. 3A). After image-guided level identification, the open mini-thoracotomy approach was performed with the assistance of an access thoracic surgeon. Segmental vessels were divided if needed. The high-speed drill was also navigated by means of an instrument reference frame (IRF) (Fig. 3B). After reaming of the corresponding rib head, pedicle, and posterior part of the vertebral body, the discectomy and TDH resection were performed under microscope magnification and continuous matching with image guidance (Fig. 3C). At the end of the operation, a 3D scan was acquired to confirm complete decompression of the spinal canal. Before the closure of the thoracotomy wound, the excluded lung was reinflated, and a chest tube was placed. This was usually removed 24-72 hours after surgery.

\section{Clinical Results}

The characteristics of patients are reported in Table 1. Five men and 3 women underwent surgery for TDH between 2017 and 2019. The mean age was 49 years (range, 46-66 years). All patients had clinical signs of cord compression preoperatively, including lower limbs sensorimotor deficits; walking difficulties and ataxia; and cauda equina signs 

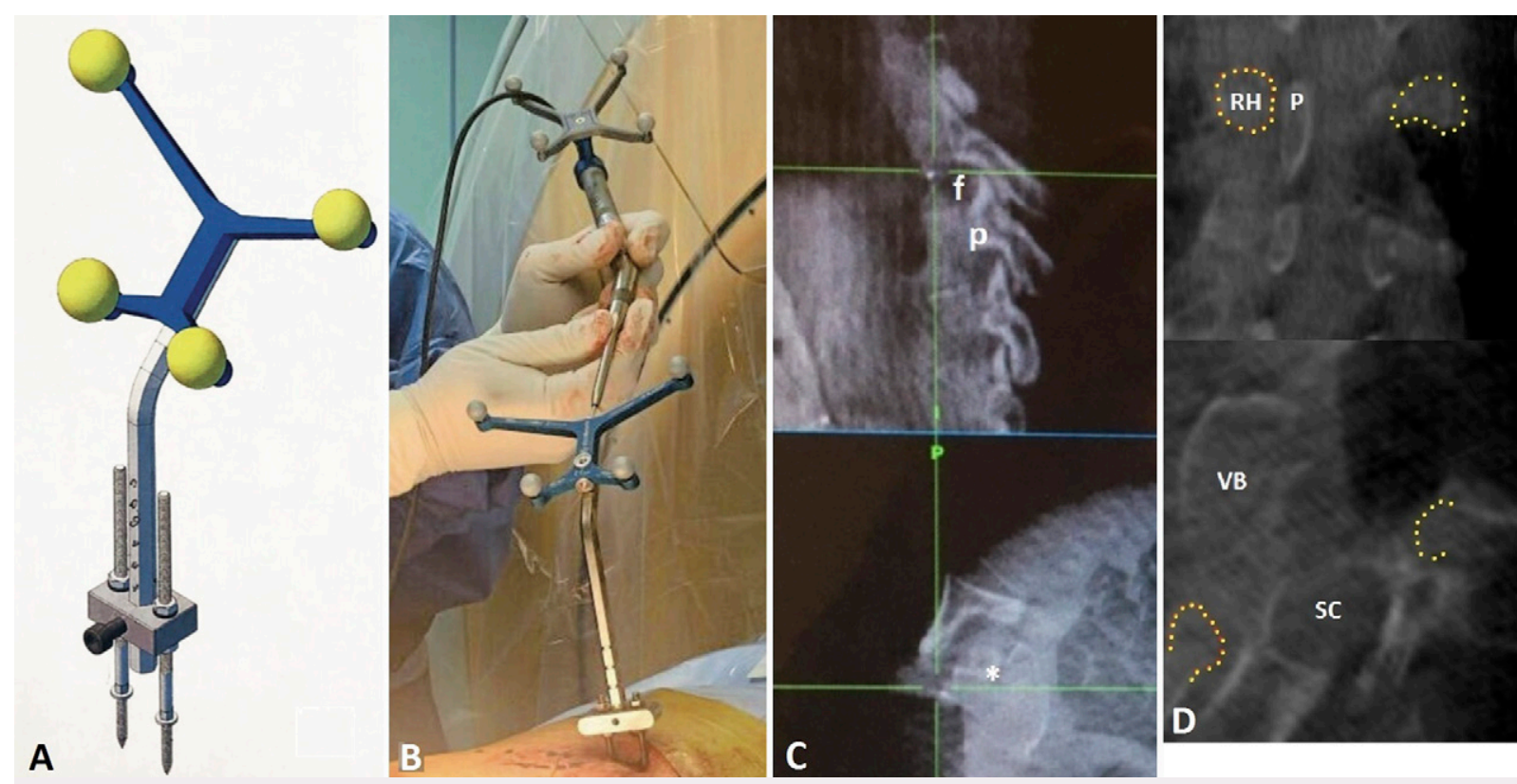

FIG. 3. A: Our self-designed iliac wing PRF. Note the double-pin fixation PRF holder (courtesy of Dr. Roccucci). B: Navigated high-speed drill during instrument verification. Note the IRF secured to the drill grip. C: Intraoperative navigation snapshot during pedicle drilling. The intersection of the green lines indicates the real-time drill tip position. The asterisk indicates the TDH. D: Coronal (top) and axial (bottom) intraoperative snapshots showing the reduced need of rib head resection on the left side, if compared with the contralateral rib (yellow dots). $f=$ foramen; $p=$ pedicle; $\mathrm{RH}=$ rib head; $S C=$ spinal canal; $V B=$ vertebral body.

such as bowel, urinary, and sexual impairment. One patient (patient 2) had previously undergone surgery with a posterior approach, and he presented clinical persistence of symptoms and radiological evidence of incomplete resection. Preoperative Frankel grade was $C$ in 6 patients and $D$ in 2 patients. The affected level was T4-5 in 1 case, T6-7 in 2 cases, T8-9 in 2 cases, and T12-L1 in 3 cases. TDH was calcified in 6 cases, and soft in the remaining 2.

The thoracotomy was right-sided in 3 cases and left-sided in 5 cases. Sectioning of the diaphragm was performed in 3 patients (T12-L1 cases). Complete TDH resection was confirmed by postoperative investigations (Fig. 4), and fixation was deemed unnecessary in the totality of patients (except the patient with previous laminectomy). No dural tears occurred. We had 2 postoperative complications (25\%), both related to the surgical approach: 1 case of pleural effusion and 1 case of abdominal wall weakness, which were both treated conservatively. At 12 months follow up, all patients were ambulatory, and no deterioration occurred. Seven out of 8 patients $(87 \%)$ experienced a postoperative neurological improvement (5 patients passed from Frankel grade $C$ to D; 2 patients passed from $D$ to $E$ ), and 1 did not improve (Frankel D).

\section{Discussion}

Symptomatic TDH is a relatively rare but potentially devastating condition, and the management of these patients still represents a challenge for the spine surgeon. Calcification, or even ossification, of TDH is observed in almost half of cases. ${ }^{1,2,5}$ Intradural extension has also been described. ${ }^{2,9}$ Myelopathy has been found to be more

TABLE 1. Characteristics of patients

\begin{tabular}{|c|c|c|c|c|c|c|c|c|}
\hline Patient & $\begin{array}{l}\text { Age } \\
\text { (Yrs) }\end{array}$ & Sex & $\begin{array}{l}\text { Preoperative } \\
\text { Frankel Grade }\end{array}$ & TDH Level & $\begin{array}{c}\text { TDH } \\
\text { Consistency }\end{array}$ & $\begin{array}{l}\text { Thoracotomy } \\
\text { Side }\end{array}$ & Complication & $\begin{array}{c}\text { Frankel Grade } \\
\text { at } 12 \mathrm{Mo}\end{array}$ \\
\hline 1 & 46 & $\mathrm{~F}$ & C & T8-9 & C & Lt & - & $\mathrm{D}$ \\
\hline 2 & 66 & M & C & T12-L1 & $S$ & Rt* & - & D \\
\hline 3 & 54 & M & D & T12-L1 & $C$ & Lt* & - & $E$ \\
\hline 4 & 65 & $\mathrm{~F}$ & C & T8-9 & C & $\mathrm{Rt}$ & Pleural effusion & $\mathrm{D}$ \\
\hline 5 & 59 & M & C & T12-L1 & $S$ & Rt* & Abdominal wall weakness & $\mathrm{D}$ \\
\hline 6 & 56 & M & D & T6-7 & C & Lt & - & $E$ \\
\hline 7 & 48 & M & D & T6-7 & C & Lt & - & $\mathrm{D}$ \\
\hline 8 & 48 & $\mathrm{~F}$ & C & T4-5 & C & $\mathrm{Lt}$ & - & $\mathrm{D}$ \\
\hline
\end{tabular}

$\mathrm{C}=$ calcified; $\mathrm{S}=$ soft.

Characteristics include age, sex, preoperative and final follow-up Frankel grade, involved level, TDH consistency, thoracotomy side, and complications. The dashes indicate that no complication occurred.

* Phrenotomy. 


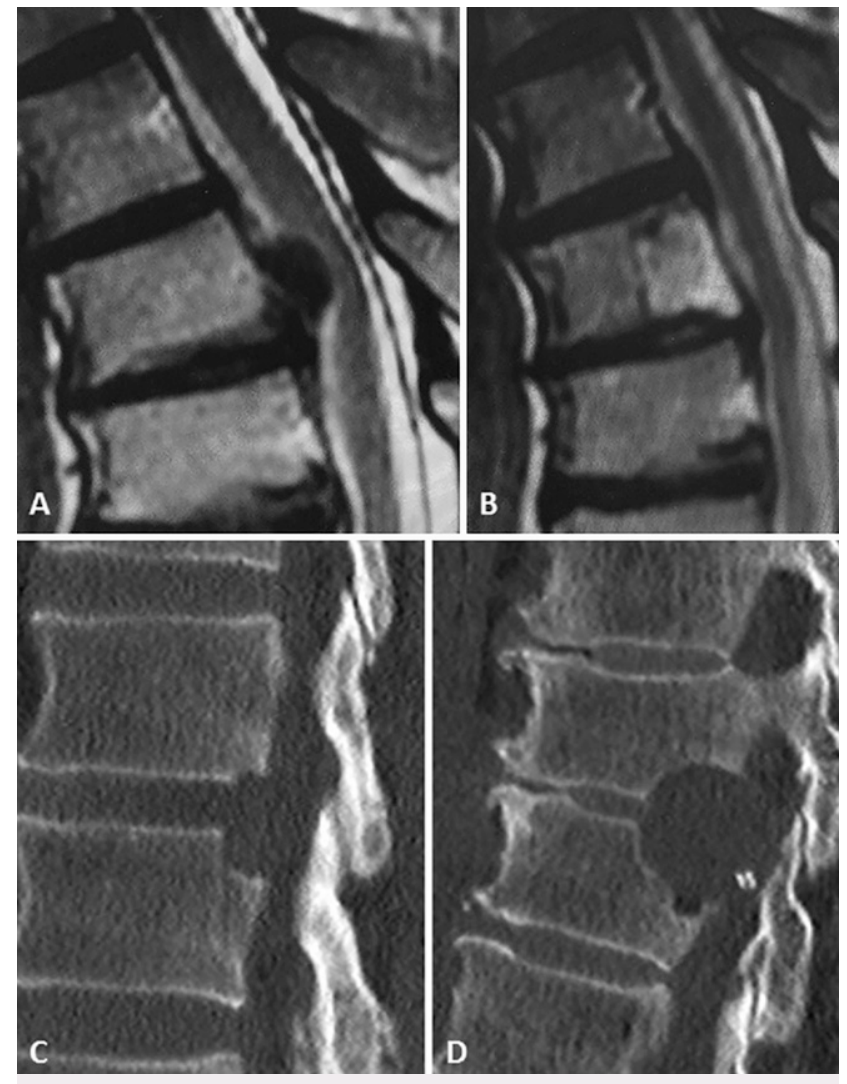

FIG. 4. Preoperative (A) and postoperative (B) sagittal magnetic resonance image showing complete resection of a T4-5 calcified TDH. Note the partial and targeted drilling of the T4 vertebral body, allowing for adequate TDH exposure. $\mathbf{C}$ and $\mathbf{D}$ : Show other examples of tailored bony resection, according to patient and TDH characteristics.

frequent in calcified TDH $(70 \%-90 \%)$, if compared with soft herniations $(50 \%) .{ }^{4,5}$ Regional thoracic cord vulnerability, due to poor vascularization ("watershed zone"), in association with a high cord/canal transverse ratio, may explain the severity of clinical manifestations and the risk of postoperative worsening. ${ }^{3,9,11}$ As much as laminectomy has almost been abandoned, the gold standard approach has not yet been identified. Currently used approaches can be divided in posterolateral (transpedicular, transfacet pedicle sparing), lateral (costotransversectomy, lateral extracavitary), and anterior transthoracic (open thoracotomy or thoracoscopy and their minimally invasive and retropleural variations). ${ }^{4,12-18}$ Anterior transthoracic approaches have been developed in order to directly access the lesion, reduce the need for dural retraction, and achieve complete removal of TDH. ${ }^{8,9,19}$ However, the anatomy of the thorax is peculiar and often unfamiliar to neurosurgeons and orthopedic spine surgeons. In particular, the sectioning of the diaphragm, manipulation of the pleura, and retraction of lung and great vessels might be hazardous. Thoracic discectomy has a reported complication rate of $20 \%-30 \%$, with whatever technique used, ${ }^{19-21}$ and the patient must be informed about this remarkable risk. Besides neurological impairment, dural fistulas, and incomplete TDH resection, ${ }^{22}$ complications of transthoracic procedures include lung-related conditions (such as atelectasis and pleural effusion) and intercostal neuralgia. ${ }^{1,2,5,7-9,19,21}$ Moreover, the risk of wrong-level surgery (WLS) has to be taken in consideration, as it is not so infrequent in thoracic spine operations. In a series of $15 \mathrm{TDH}$ patients undergoing reoperation, WLS was found to be the main indication in 5 cases. ${ }^{23}$

Since localization of the involved level can be difficult, several marking techniques have been proposed: adhesive skin markers, percutaneous dye injection (spinous process or pedicle), vertebroplasty, insertion of K-wires or subperiosteal rib harpoon, and coiling of the corresponding intercostal artery. ${ }^{1,2,4,5}$ In our case series, level identification was readily achieved by means of navigation of the initial O-Arm scan, and no WLS occurred.

\section{Observations}

Only a few studies can be found in the literature, describing the use of spinal navigation for anterior thoracic spine operations. ${ }^{24-27}$ In 2014, both Johnson et al. ${ }^{27}$ and Hur et al. ${ }^{26}$ reported the use of navigation for the thoracoscopic treatment of TDH, ossification of posterior longitudinal ligament, infection, and tumor. The authors agree on the fact that the use of intraoperative navigation leads to a better understanding of intrathoracic anatomy, optimized trajectory of bone drilling, and reduced radiation exposure. Although the authors report that they secured the PRF to the spinous process, we believe that this could hamper the surgeon's comfort and interfere with the movements of the surgical table in relation to the O-Arm. In addition, iliac crest pins provide a more appropriate visibility of the PRF by the Stealth Station camera with the patient in lateral decubitus ${ }^{10}$ (Fig. 2B). In our experience, surgeon's comfort and PRF visibility overcome the disadvantage of an additional iliac crest skin incision.

Intraoperative navigation represents an important tool, both for level identification and the intrathoracic part of the procedure. The costovertebral joint is a crucial structure in terms of preparation of the access to the pathology. ${ }^{4,6}$ If compared with the former unnavigated discectomies, we observed a reduced need of rib head resection during disc and foraminal exposure (Fig. $3 \mathrm{C}$ and D). This was mostly perceived in the lower levels (T8-L1), probably because the pedicle is less overlapped by the rib head in the caudal thoracic spine. ${ }^{28}$

As drilling proceeds through the vertebral body, anatomical findings are continuously matched with the information provided by navigation, thus allowing the surgeon to be aware of the drill tip position relative to the intervertebral foramen, spinal canal, and TDH. Despite our relatively small series, the results reported in this paper corroborate the usefulness of image-guided surgery in TDH resection. However, a sound knowledge of thorax and anterior spine anatomy is required, and navigation should be primarily used as a confirmation of intraoperative anatomical landmarks.

\section{Lessons}

In order to increase the safety of anterior surgical approaches, we applied the concepts of spinal navigation to the thoracotomy setting. In particular, the PRF is suitably adapted for the iliac wing, and the high-speed drill is also integrated in the navigation system. The advantages of this technique include decrease in WLS, continuous matching of intraoperative and navigation anatomical findings, safer orientation in the thoracic cavity, reduced need of rib resection, optimized vertebral body drilling, better visualization of the TDH location and extent, intraoperative confirmation of complete excision, and restrained risk of neurological damage. In our report, we achieved a safe and complete resection of the TDH in all patients, without neurological complications. In conclusion, we consider spinal navigation as an important resource for the surgical management of patients with TDH. 


\section{References}

1. Bouthors $C$, Benzakour A, Court C. Surgical treatment of thoracic disc herniation: an overview. Int Orthop. 2019;43(4):807-816.

2. Court C, Mansour E, Bouthors C. Thoracic disc herniation: surgical treatment. Orthop Traumatol Surg Res. 2018;104(1S):S31-S40.

3. Quint U, Bordon G, Preissl I, et al. Thoracoscopic treatment for single level symptomatic thoracic disc herniation: a prospective followed cohort study in a group of 167 consecutive cases. Eur Spine J. 2012;21(4):637-645.

4. Quraishi NA, Khurana A, Tsegaye MM, et al. Calcified giant thoracic disc herniations: considerations and treatment strategies. Eur Spine J. 2014;23(1 suppl):S76-S83.

5. Yoshihara $\mathrm{H}$. Surgical treatment for thoracic disc herniation: an update. Spine (Phila Pa 1976). 2014;39(6):E406-E412.

6. Arts MP, Bartels RH. Anterior or posterior approach of thoracic disc herniation? A comparative cohort of mini-transthoracic versus transpedicular discectomies. Spine J. 2014;14(8):1654-1662.

7. Elhadi AM, Zehri AH, Zaidi HA, et al. Surgical efficacy of minimally invasive thoracic discectomy. J Clin Neurosci. 2015;22(11): 1708-1713.

8. Lubelski D, Abdullah KG, Steinmetz MP, et al. Lateral extracavitary, costotransversectomy, and transthoracic thoracotomy approaches to the thoracic spine: review of techniques and complications. J Spinal Disord Tech. 2013;26(4):222-232.

9. Robinson WA, Nassr AN, Sebastian AS. Thoracic disc herniation, avoidance, and management of the surgical complications. Int Orthop. 2019;43(4):817-823.

10. Roccucci P, Peron S, Stefini R. Navigazione Vertebrale, Indicazioni di Pratica Clinica. Griffin-Timeo Editore; 2019

11. Shamji MF, Maziak DE, Shamji FM, et al. Circulation of the spinal cord: an important consideration for thoracic surgeons. Ann Thorac Surg. 2003;76(1):315-321.

12. Foreman PM, Naftel RP, Moore TA 2nd, Hadley MN. The lateral extracavitary approach to the thoracolumbar spine: a case series and systematic review. J Neurosurg Spine. 2016;24(4):570-579.

13. Moran C, Ali Z, McEvoy L, et al. Mini-open retropleural transthoracic approach for the treatment of giant thoracic disc herniation. Spine (Phila Pa 1976). 2012;37(17):E1079-E1084.

14. Roelz R, Scholz C, Klingler JH, et al. Giant central thoracic disc herniations: surgical outcome in 17 consecutive patients treated by mini-thoracotomy. Eur Spine J. 2016;25(5):1443-1451.

15. Russo A, Balamurali G, Nowicki R, et al. Anterior thoracic foraminotomy through mini-thoracotomy for the treatment of giant thoracic disc herniations. Eur Spine J. 2012;21(2 suppl): S212-S220.

16. Sharma SB, Kim JS. A review of minimally invasive surgical techniques for the management of thoracic disc herniations. Neurospine. 2019;16(1):24-33.

17. Uribe JS, Smith WD, Pimenta L, et al. Minimally invasive lateral approach for symptomatic thoracic disc herniation: initial multicenterzc clinical experience. J Neurosurg Spine. 2012;16(3):264-279.

18. Xiaobing Z, Xingchen L, Honggang Z, et al. "U" route transforaminal percutaneous endoscopic thoracic discectomy as a new treatment for thoracic spinal stenosis. Int Orthop. 2019;43(4):825-832.

19. Kerezoudis P, Rajjoub KR, Goncalves S, et al. Anterior versus posterior approaches for thoracic disc herniation: association with postoperative complications. Clin Neurol Neurosurg. 2018;167:17-23.
20. Wait SD, Fox DJ Jr, Kenny KJ, et al. Thoracoscopic resection of symptomatic herniated thoracic discs: clinical results in 121 patients. Spine (Phila Pa 1976). 2012;37(1):35-40.

21. Yoshihara $H$, Yoneoka D. Comparison of in-hospital morbidity and mortality rates between anterior and nonanterior approach procedures for thoracic disc herniation. Spine (Phila Pa 1976). 2014;39(12):E728-E733.

22. Dützmann S, Rose R, Rosenthal D. Revision surgery in thoracic disc herniation. Eur Spine J. 2020;29(suppl 1):39-46.

23. Dickman CA, Rosenthal D, Regan JJ. Reoperation for herniated thoracic discs. J Neurosurg. 1999;91(2 suppl):157-162.

24. Assaker R, Reyns N, Pertruzon B, et al. Image-guided endoscopic spine surgery: part II: clinical applications. Spine (Phila Pa 1976). 2001;26(15):1711-1718.

25. Campos WK, Gasbarrini A, Boriani S. Case report: curetting osteoid osteoma of the spine using combined video-assisted thoracoscopic surgery and navigation. Clin Orthop Relat Res. 2013;471(2): 680-685.

26. Hur JW, Kim JS, Cho DY, et al. Video-assisted thoracoscopic surgery under $\mathrm{O}$-arm navigation system guidance for the treatment of thoracic disk herniations: surgical techniques and early clinical results. J Neurol Surg A Cent Eur Neurosurg. 2014;75(6): 415-421.

27. Johnson JP, Drazin D, King WA, Kim TT. Image-guided navigation and video-assisted thoracoscopic spine surgery: the second generation. Neurosurg Focus. 2014;36(3):E8.

28. Chen F, Liu X, Wang G, et al. Anatomic relationship of bony structures in pedicle-rib unit and its significance. World Neurosurg. 2020;139:e691-e699.

\section{Disclosures}

The authors report no conflict of interest concerning the materials or methods used in this study or the findings specified in this paper.

\section{Author Contributions}

Conception and design: Rusconi, Roccucci. Acquisition of data: Rusconi, Roccucci, Peron. Analysis and interpretation of data: all authors. Drafting the article: Rusconi, Stefini. Critically revising the article: Rusconi, Stefini. Reviewed submitted version of manuscript: Rusconi. Approved the final version of the manuscript on behalf of all authors: Rusconi. Statistical analysis: Rusconi. Administrative/technical/ material support: Roccucci, Peron. Study supervision: Roccucci, Stefini.

\section{Supplemental Information}

Previous Presentations

The scientific material reported in this study was presented as an e-poster at the European Association of Neurosurgical Societies 2020 virtual congress, Belgrade, Serbia, October 19-21, 2020.

Patient Informed Consent

The necessary patient informed consent was obtained in this study.

\section{Correspondence}

Angelo Rusconi: Azienda Socio-Sanitaria Territoriale Ovest Milanese, Legnano Civil Hospital, Milan, Italy. angelo.rusconi@hotmail.com. 